\title{
DIFFERENCES OF EFFICIENCY OF TREATMENT OF ISOLATED GROWTH HORMONE DEFICIENCY AND PANHYPOPITUITARISM IN CHILDREN IN REAL CLINICAL PRACTICE
}

\author{
Ekaterina Rudkova'; Ivan Grisuk ${ }^{1}$ \\ ${ }^{1}$ Belarusian State Medical University, ${ }^{2}$ Republican Center for Pediatric Endocrinology (KZ "2nd Children's Hospital", Minsk) \\ e-mail: ekaterinarudkova@mail.ru
}

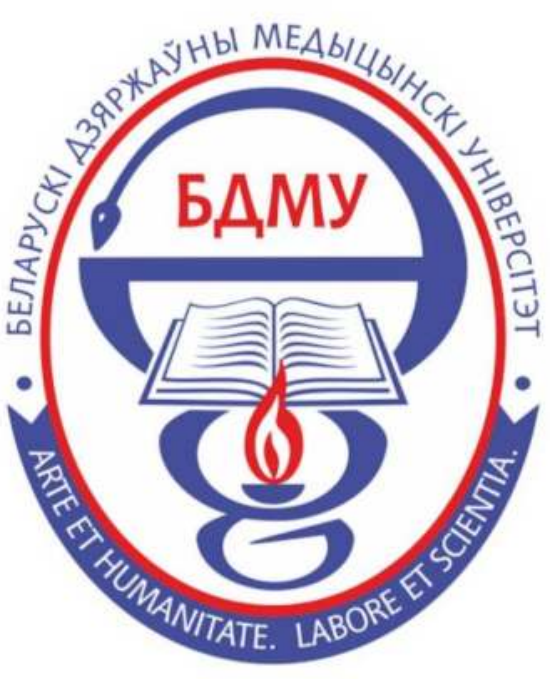

\author{
KM "2ND CITY CHILDREN'S \\ HOSPITAL"
}

\section{Introduction}

Deficiency of growth hormone $(\mathrm{GH})$ in children is manifested by pronounced stunting (below -2 sigmal abnormalities (SD)), changes in body composition (increase in fat mass and decrease in muscle mass), violation of blood lipid composition and glucose metabolism, development of metabolic syndrome, increase in levels of C-reactive protein and profuse cytokines. Somatotropic insufficiency may be caused by a decrease in or complete absence of only $\mathrm{GH}$ (isolated form of GH deficiency) or a decrease in the synthesis of tropic pituitary hormones. Frequency of occurrence varies from 1:4000 to 1:10000 newborns.

\section{Objective}

To assess the effectiveness of treatment in real clinical practice by comparing the dynamics of growth of those with isolated growth hormone deficiency (IGHD) and of those with panhypopituitarism (PHP).

\section{Materials and methods}

Medical History of 47 patients aged from 3 to 18 years diagnosed with IGHD and PHP in 2006-2018 have been analyzed in the Republican Center for Pediatric Endocrinology (KZ "2nd Children's Hospital", Minsk). Microsoft Excel, SPSS have been used for statistical data analysis. The retrieved data for all indicators in the study have been expressed as a percentage $(\%)$, in absolute values $(n)$, and $M \pm \sigma$ has been specified as well.

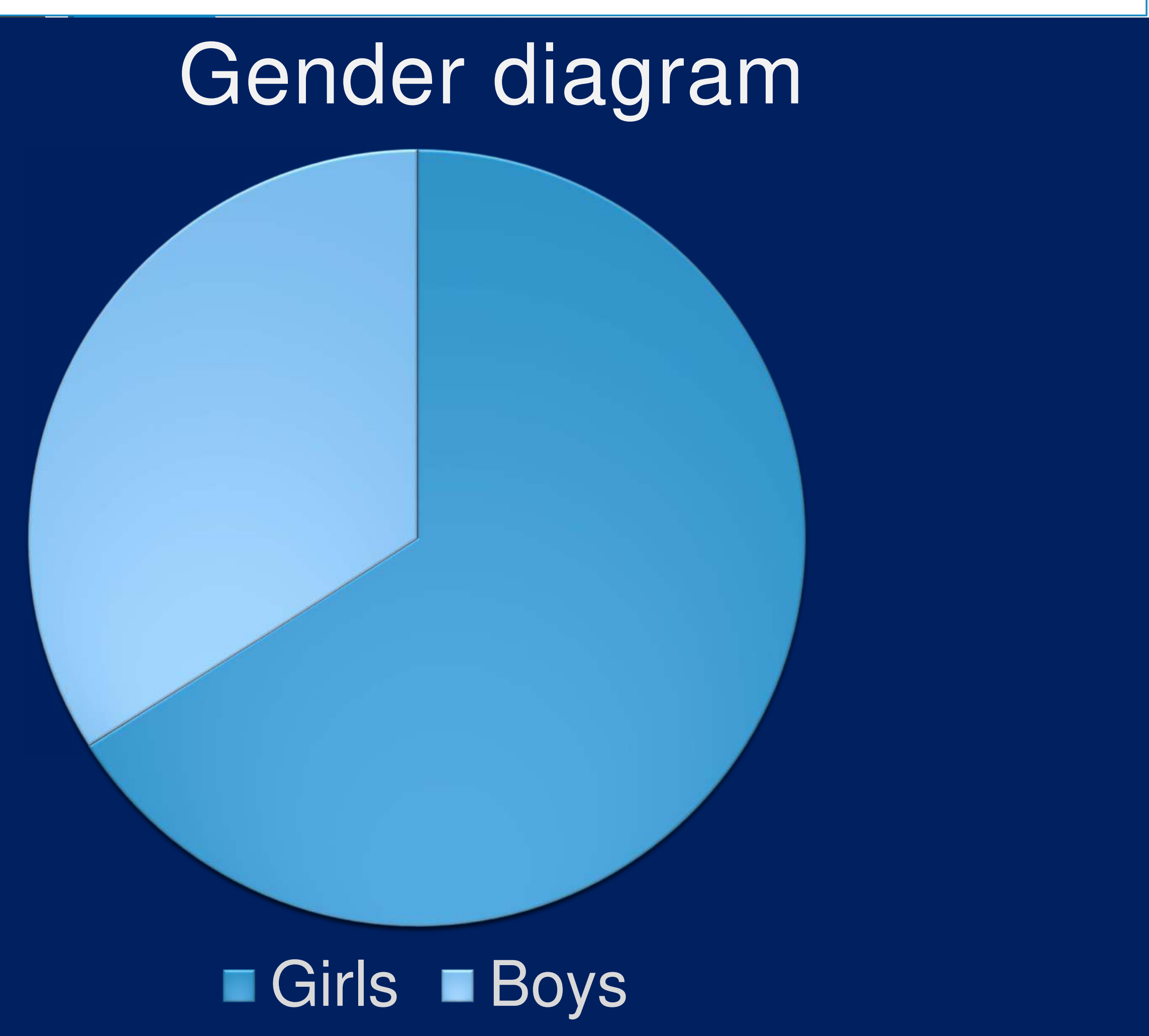

Among 47 patients participating in the study (66\% girls, 34\% boys) eighty-three per cent (83\%) is with IGHD and seventeen per cent (17\%) with PHP. It was revealed that before treatment, 36 patients had a significantly short stature (from -6 to -2.01 SDS); SDS of 11 patients (2 of them with PHP) was from -1.9 to 1. At the time of diagnosis, the mean height SDS was -2.4 in children with IGHD, while after completion of treatment, SDS was $-1,4$; height SDS was -2.7 before treatment and -0.8 after completion of treatment in children with PHP.

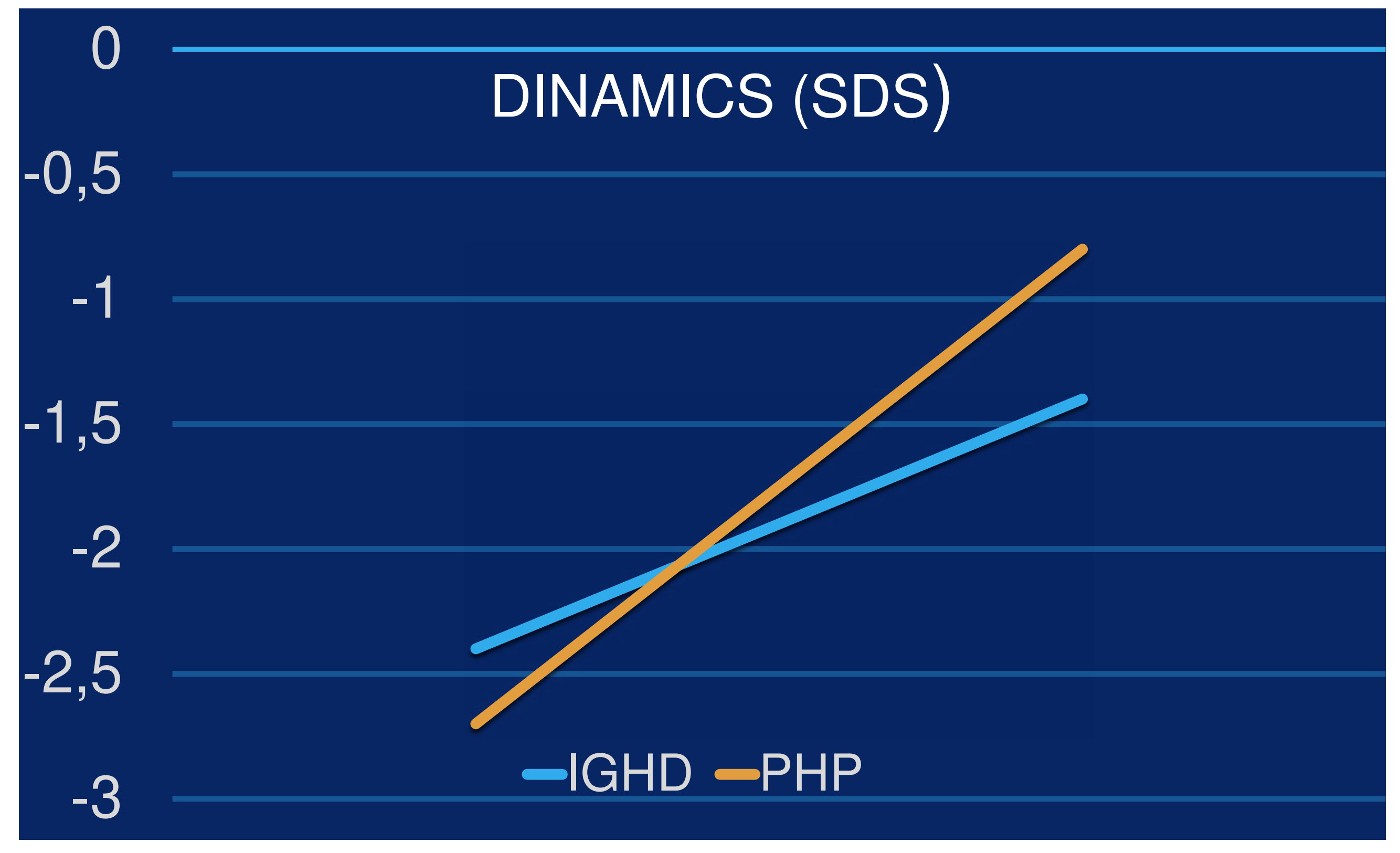

The largest values of STH maximum level according to stimulation tests (at least 2) was $6.8 \pm 5.2 \mathrm{ng} / \mathrm{ml}$ in group of those with IGHD and $2.56 \pm 1.65 \mathrm{ng} / \mathrm{ml}$ in group of those with PHP ( $p$ $<0.05)$. At the time of diagnosis, IGF-1 was below normal range in $76.6 \%$ of patients, after completion of treatment it was below normal range in $46.68 \%$ of patients; at the same time, the IGF-1 level in the group of those with PHP was lower compared to the IGHD group ( $p<0.05$ ) and were observed in $87.5 \%$ of children. After $\mathrm{GH}$ treatment completion, IGF-1 remained below reference values in $87.5 \%$ of patients with PHP. A lagging of the bone age from the passport in the IGHD group before treatment was 2 years 5 months \pm 1 year 3 months, after treatment it was 2 years 5 months \pm 2 years; while in the group with PHP it was 2 years 11 months \pm 1 year 4 months before treatment and 3 year 7 months \pm 4 year 7 months after treatment $(p<0.05)$. During MRI, the pathology of the pituitary gland and surgical interventions for tumor neoplasms were detected in $36.2 \%$ of the patients. The average dynamics of growth during the entire period of treatment in patients with IGHD is $6.9 \pm 1.62 \mathrm{~cm} /$ year, while in patients with PHP it is $7.9 \pm 4.3 \mathrm{~cm} /$ year $(p<0.05)$. In addition to treatment with $\mathrm{GH}, 100 \%$ of patients from the group with PHP also received levothyroxine, $50 \%$ of those received hydrocortisone, $12.5 \%$ of such patients received desmopressin.

\section{Conclusion}

Comparative analysis of the effectiveness of growth hormone treatment in real clinical practice showed a significant dynamics of growth, more obvious in patients with panhypopituitarism. 